\title{
is Research Square \\ Design of High Performance Hybrid Plasmonic Modulator Based on ITO and Graphene
}

Omid Abbaszadeh-Azar

Shahid Beheshti University

kambiz abedi ( $\sim$ k_abedi@sbu.ac.ir)

Shahid Beheshti University https://orcid.org/0000-0001-5014-1037

\section{Research Article}

Keywords: Graphene, ITO, Hybrid plasmonic, Silicon on insulator, Modulator

Posted Date: January 17th, 2022

DOI: https://doi.org/10.21203/rs.3.rs-1226142/v1

License: (c) (1) This work is licensed under a Creative Commons Attribution 4.0 International License. Read Full License 


\section{Abstract}

In this paper, a hybrid plasmonic modulator based on ITO and graphene is designed. Graphene and ITO are used in the active region, which increases the light-matter interaction and reduces the device's operating voltage in the proposed modulator. As a result, it increases the extinction ratio (ER) and reduces the proposed modulator's power consumption and device footprint compared to similar modulators. The values of 8.12 $\mathrm{dB} / \mu \mathrm{m}$ and $5.4 \mathrm{fJ}$ are obtained for ER and power consumption, respectively. The time-domain finitedifference (FDTD) method is used to simulate the modulator. Integrating a modulator with high light-matter interaction and low power consumption in the silicon-on-insulator platform has significant potential for broadband, compact and efficient communication interconnects and circuits.

\section{Introduction}

One of the key elements in optical electronics is the silicon-based optical modulator, connecting the two fields of photonics and electronics by converting an electrical signal into an optical signal. The key characteristics of the optical modulator are low power consumption, compact size, high extinction ratio (ER), and low insertion losses. Therefore, designing optical modulators with optimum parameters is essential. The architecture of typical modulators such as silicon-based structures (Xu et al., 2005, Preston et al., 2009), high-quality resonant structures (Li et al., 2018, Qiu and Han, 2021), and Mach Zehnder structures (Mahmoud et al., 2017, Jiang et al., 2018) are rarely able to optimize all modulator parameters simultaneously. Such structures have drawbacks such as narrow bandwidth, high-energy consumption, and large size. Developing new modulators with compact size and broadband is required (Babicheva et al., 2013). Metal oxide semiconductor-based hybrid plasmonic waveguides are used to design compact, broadband silicon-based optical modulators. These waveguides use doped silicon, Indium Tin Oxide (ITO), vanadium dioxide, or graphene (Kim and Kim, 2016, Du et al., 2019, Babicheva et al., 2013, Liu et al., 2011a, Wong and Helmy, 2017). A fundamental characteristic of these materials is adjusting the density of carriers and injecting charge into the material by applying an electric field (Lin and Helmy, 2015b, Koch et al., 2016, Shah et al., 2018, Jin et al., 2016, Wood et al., 2018). Recently, directional coupler-based devices have been investigated (Kim, 2014, Kim and Kim, 2016, Du et al., 2019). In these structures, the coupling rate and attenuation coefficient change, and the input signal can be modulated by changing the density of plasmonic material carriers in the coupler.

Plasmonic structures enhance light-matter interaction in optical devices and form a strong local field interaction with plasmonic resonances. Based on this, combined plasmonic waveguide modulators (HPW) (Lin and Helmy, 2015b, Wood et al., 2018, Campione et al., 2017, Huang et al., 2016, Zhu et al., 2017) and Metal-Insulator-Metal (MIM) (Lee et al., 2014, Wu and Xu, 2018) have been introduced. In these structures, high optical field confinement leads to increasing interaction of light and matter. In recent years, graphene as an active element in optical modulators has been considered. Graphene has unique properties such as a unique linear energy band, high carrier mobility at room temperature, and controllable light transmission and carrier density by applying electric media. These properties have led to the widespread use of graphene in electro-optical modulators from the visible range to terahertz (Chen et al., 2016, Liu et al., 2011b, SensaleRodriguez et al., 2012, Ansell et al., 2015, Han et al., 2020, Sun et al., 2019). However, these structures suffer 
from low ER due to poor interaction between graphene and light-wave. Therefore, increasing the interaction between optical signals with graphene is essential for achieving optical devices that use graphene adjustability (Ye et al., 2014).

On the other hand, ITO-based modulators have high ER but suffer from high operating voltages and high power consumption. The ITO layer can be used in graphene plasmonic waveguides to increase graphenebased modulator and optical signal interaction (Das et al., 2015, Ye et al., 2014).

This paper proposes and designs a plasmonic modulator based on ITO and graphene. The modulator structure consists of two silicon waveguides which a coupler is coupling these two waveguides. The coupler consists of a vertical Si/Graphene/ $\mathrm{HfO}_{2} / \mathrm{ITO} / \mathrm{HfO}_{2} / \mathrm{Graphene}$ stack. The use of ENZ properties of graphene and ITO materials has led to the design of modulators with low operating voltage and high resolution. The optical properties of the proposed modulator are investigated using the FDTD method.

\section{Configuration And Characterization Of Hybrid Plasmonic Waveguide}

Figure 1 shows the proposed modulator structure, which consists of three waveguides. Two of them are silicon waveguides, and one is a plasmonic waveguide, which is placed between the two silicon waveguides. The plasmonic waveguide comprises ITO and multilayer graphene separated by $\mathrm{HfO}_{2}$ dielectric and two silicon layers. The ITO and graphene layers are sandwiched between two layers of silicon.

The height and width of the two outer silicone waveguides $\mathrm{H}_{\mathrm{Si}}$ and $\mathrm{W}_{\mathrm{Si}}$ are assumed. The width and height of the middle waveguide are $\mathrm{W}_{\mathrm{PL}}$ and $\mathrm{H}_{\mathrm{PL}}$, respectively. The height of the ITO layer is $\mathrm{H}_{I T O}$, and the height of the $\mathrm{HfO}_{2}$ layer is $\mathrm{H}_{\mathrm{HfO} 2}$.

To investigate the epsilon near zero (ENZ) effect of two materials (ITO and graphene), we model the ITO and graphene using the Drude-Lorentz model and the Kubo formula, respectively.

At first, the refractive index of graphene will be investigated, which is related to its dynamic conductivity. The conductivity of graphene can be described using the Kobo equation, as follows (Shin and Kim, 2015, Gosciniak and Tan, 2013, Chen et al., 2016):

$\sigma(\omega)=\frac{-i e^{2}}{\Pi \hbar^{2}(\omega+i 2 \Gamma)}\left(\frac{\mu_{c}}{k_{B} T}+2\left(e^{\frac{-\mu_{c}}{k_{B} T}}+1\right)\right)+\frac{-i e^{2}(\omega+i 2 \Gamma)}{\Pi \hbar^{2}}\left[\int_{0}^{\infty} \frac{\partial f_{d}(-\varepsilon)-\partial f_{d}(\varepsilon)}{(\omega+i 2 \Gamma)^{2}-4(\varepsilon / \hbar)^{2}} d \varepsilon\right]$

1

$\mathrm{kB}$ is the Boltzmann constant, $\mathrm{T}$ is the temperature, $f_{d}(\varepsilon)=\left(e^{\varepsilon-\mu_{c}} / k_{B} T+1\right)^{-1}$ is the Fermi-Dirac distribution, $\hbar$ is the reduced Planck's constant, $\mu \mathrm{c}$ is the chemical potential, $\Gamma=1 / \tau$ is the charged particle scattering rate, and $\omega$ is the angular frequency. 
The relationship between voltage and chemical potential is defined $\mu_{C}=\hbar v_{F} \sqrt{\Pi\left|a_{0} V\right|}$, where $v_{\mathrm{F}}$ is the Fermi velocity in graphene and $a_{0}=9 \times 10^{16} \mathrm{~m}^{-2} V^{-1}$.

Surface permittivity is obtained using graphene conductivity $\left(\sigma=\sigma^{\prime}+i \sigma^{\prime \prime}\right)$, at room temperature and $\lambda=$ $1.55 \mu \mathrm{m}$ :

$$
\varepsilon_{g}=1+\frac{i \sigma\left(\omega, \mu_{c}\right)}{\omega \varepsilon_{0} \delta}
$$

\section{2}

$\delta=1 \mathrm{~nm}$ is the effective thickness of graphene (Shin and Kim, 2015, Gosciniak and Tan, 2013). The real part of the permittivity changes from positive to negative values as the chemical potential increased (Shin and Kim, 2015).

An ITO layer has been used in the plasmonic waveguide to increase the interaction between the graphene and optical fields (Feigenbaum et al., 2010). The ITO permittivity is described using the Drude-Lorentz model (equation 1) (Chee et al., 2012, Lou et al., 2012).

$$
\epsilon=\epsilon_{\infty}-\frac{\omega_{p}^{2}}{\omega^{2}+i \gamma \omega}
$$

3

$$
\omega_{p}^{2}=\frac{N e^{2}}{\epsilon_{\infty} m^{*}}
$$

4

$\varepsilon_{\infty}=3.9$ is the high-frequency permittivity of ITO. $m^{*}=0.35 m_{0}$ is the effective mass of electrons, and, $m_{0}$ indicates the charge and mass of electrons. $\omega_{p}$ is plasma frequency, and $\gamma=1.84 \times 10^{14} \mathrm{rad} / \mathrm{srepresents}$ electron scattering rate. $\mathrm{N}$ is the carrier concentration of electrons in the ITOs accumulation layer, which its thickness is $1 \mathrm{~nm}\left(\mathrm{~W}_{\mathrm{a}}\right)$ according to the Tomas-Fermi screening theory (Krasavin and Zayats, 2012, Kim and Kim, 2016). $\mathrm{N}$ is described as a function of voltage ( $\mathrm{V}$ ) as below equation (Jiang et al., 2019a):

$$
N=N_{0}+\frac{\varepsilon_{0} \cdot \varepsilon_{\mathrm{HfO}_{2}} \cdot V}{e . H_{\mathrm{HfO}_{2}} \cdot W_{a}}
$$

\section{5}

It was assumed that $\mathrm{NO}=1 \times 10^{19} \mathrm{~cm}^{-3}, \varepsilon_{\mathrm{HfO}_{2}}=25, H_{\mathrm{HfO}_{2}}=10 \mathrm{~nm}, W_{\mathrm{a}}=1 \mathrm{~nm}$ and $\mathrm{\bigotimes}_{0}$ is the vacuum permittivity. High charge concentration in accumulation layers is reachable because of the high DC permittivity of $\mathrm{HfO}_{2}\left(\varepsilon_{\mathrm{HfO}_{2}}=25\right)$. As voltage increases, the accumulation layer's carrier concentration and permittivity's imaginary part increases. The real part of ITO's permittivity changes from positive to zero (ENZ state) and negative values, and as a result, the ITO changes from dielectric state to metallic state (Alù et al., 
2008). In the ENZ state, the electrical displacement components must be continuous at the interface of the ITO and dielectric $\left(\varepsilon_{\mathrm{HfO}_{2}} E_{\mathrm{HfO}_{2}}=\varepsilon_{I T O} E_{I T O}\right)$. It causes significant confinement of the electrical field in the ITO and dielectric interface, and it improves the interaction of light and matter.

Figure 2(a) shows the propagation loss, and figure 2(b) shows the effective index of the device with two mono-graphene layers. The propagation loss has two peaks (one in $0.65 \mathrm{~V}$ and the other in $2.62 \mathrm{~V}$ ) related to the ENZ effect in graphene and the other to the ENZ effect in the ITO. The first peak is affected by the chemical potential of graphene, and the second peak is related to the ITO. Because the impact of ENZ on graphene has occurred at a lower voltage, if the two peaks are combined by increasing the number of graphene layers, a lower operating voltage is achieved. Modulators with this effect could have higher efficiency and lower energy consumption (Eslami et al., 2021).

As the number of graphene layers increases, the two peaks propagation loss due to the effect of ENZ on graphene and ITO merged, and the propagation loss at voltage $0.62 \mathrm{~V}$ increases (figure 2 (c)). Also, The use of a large number of graphene layers will cause the properties of graphite, and the effect of ENZ will be attenuation. Therefore, we consider 7 layers of graphene.

The intensity of the guided mode in On-state $(0 \mathrm{~V})$ and in the Off-state $(0.62 \mathrm{~V})$ is shown in figure $3(\mathrm{~b})$ and $3(\mathrm{c})$, respectively. The intensity of the guided mode in $0 \mathrm{~V}$ is distributed in the active layers in the coupling region (Figure $3(\mathrm{~b})$ ). In the $0.62 \mathrm{~V}$, it is concentrated in the ITO and graphene layer (Figure 3(c)), and high losses occur due to the ENZ effect.

\section{Design And Simulation Of Modulator}

The device was simulated with the FDTD method in $1.55 \mu \mathrm{m}$ wavelength. The refractive index of the materials is assumed to be: $n_{S i}=3.47, n_{\mathrm{SiO}_{2}}=1.44$ and $n_{\mathrm{HfO}_{2}}=1.98$ (Lin and Helmy, 2015c). $\mathrm{W}_{\mathrm{Si}}=300 \mathrm{~nm}$ and $\mathrm{H}_{\mathrm{Si}}=250 \mathrm{~nm}$ are assumed to have a device with a compact size. The guided mode did not support smaller sizes $\left(\mathrm{W}_{\mathrm{Si}}<300 \mathrm{~nm}\right)$.

The effective index of silicon and plasmonic waveguides should be matched to increase the coupling rate between waveguides and reduce the insertion loss (Huang and Mu, 2009, Abdelatty et al., 2018). Figure 4 (a) shows the change in the effective index of plasmonic and silicon waveguides by changing their width. Based on Figure $4(\mathrm{a})$, for $\mathrm{W}_{\mathrm{Si}}=300 \mathrm{~nm}$ and $\mathrm{W}_{\mathrm{PL}}=130 \mathrm{~nm}$, the two waveguide's effective index matched.

The coupling length $\left(L_{c}\right)$ is calculated by coupling theory (Jiang et al., 2019b, Ye et al., 2015, Chee et al., 2012). The device propagation mode has been found with cross-section simulation. $n_{1}, n_{2}$, and $n_{3}$ are the effective index of the eigenmodes, which are symmetric mode (mode 1), asymmetric mode (mode 2), and symmetric mode (mode 3), respectively. Eigenmodes modes should apply to equation 6 to achieve maximum output power in V=0 (Chee et al., 2012, Ye et al., 2015, Lou et al., 2012):

$$
2 n_{2}-n_{1}-n_{3}=0 \rightarrow n_{2}=\frac{n_{1}+n_{3}}{2}
$$


The effective index of eigenmode modes for different values of the gap (distance between the waveguides) is shown in figure 4 (b). $g=30 \mathrm{~nm}$ has been considered based on figure $4(\mathrm{~b})$ and equation 6 .

The coupling length is obtained by the following equation (Chee et al., 2012, Ye et al., 2015, Lou et al., 2012):

$$
L_{c}=\frac{\lambda}{2\left(n_{1}-n_{2}\right)}
$$

7

$\mathrm{L}_{\mathrm{c}}$ is equal to $L_{C}=4.9 \mu \mathrm{m}$ (in the $\lambda=1.55 \mu \mathrm{m}$ ). Figure 5 shows the coupling length with voltage change. By changing the voltage, the coupling length shows the dynamic behavior that results from the change of the real and imaginary parts of the effective index. Changing the coupling length disrupts the power coupling and thus has a role in attenuating the output power.

\section{Properties Of The Hybrid Plasmonic Modulator}

The device performance's main characteristics are presented in this section. Modulation speed, power consumption, propagation loss, and extinction ratio (ER) are investigated. The on/off extinction ratio is about $8.12 \mathrm{~dB} / \mu \mathrm{m}$; ER equals the difference between the propagation loss at the zero voltage and $0.62 \mathrm{~V}$ (ER=Loss0.62V-LossOV) (Shin and Kim, 2015). Loss in zero voltage is $0.83 \mathrm{~dB} / \mu \mathrm{m}$; also, we set the device length equal to coupling length. Figure 6 (a) shows the ER and propagation losses for different wavelengths. The proposed modulator's ER is better than modulators in (Shin and Kim, 2015, Lin and Helmy, 2015a).

Figure 6 (b) shows the propagation loss, and Figure 6 (c) shows the effective refractive index of the proposed modulator. Suggested values for the proposed modulator are the number of graphene layers $=7$, $\mathrm{H}_{\mathrm{Si}}=250 \mathrm{~nm}, \mathrm{H}_{\mathrm{PL}}=566 \mathrm{~nm}, \mathrm{H}_{\mathrm{ITO}}=10 \mathrm{~nm}, \mathrm{H}_{\mathrm{HfO} 2}=10 \mathrm{~nm}$, and $\mathrm{g}=30 \mathrm{~nm}$. Unlike figure 2 (a), figure 6 (b) shows that the propagation loss at $0.65 \mathrm{~V}$ is higher than $2.62 \mathrm{~V}$ due to increased graphene layers. As a result, the proposed modulator has a high extinction ratio and a low operating voltage.

The resistance and capacitance of the device limit the modulation speed of the optical modulator. Power consumption is also related to modulation voltage and capacitance. Figure 7(a) shows the spatial distribution of the Electrical field (E) in the On-State, and figure 7(b) shows the $E$ in the Off-State. In the Onstate input optical signal reaches the output. The input signal is attenuated, and the coupling is disturbed in the Off-State.

Capacitance is calculated by equation 8 . The capacitors are modeled with a parallel plate structure (graphene/ $\mathrm{HfO}_{2} /$ ITO interface) (Shin and Kim, 2015, Ye et al., 2015). With this definition, there are two capacitors in the structure.

$$
C=\left(\epsilon_{0} \epsilon_{O X} \frac{A}{W_{O X}}\right)=\left(W_{P L} \times L_{C} \times \epsilon_{0} \times \epsilon_{\mathrm{HfO}_{2}}\right) / \mathrm{H}_{\mathrm{HfO}_{2}}
$$


$\mathrm{C}_{\mathrm{T}}=\mathrm{C}+\mathrm{C}=28.2 \mathrm{fF}$. The modulation speed is equal to:

$$
f=\frac{1}{2 \pi R C}
$$

\section{9}

$\mathrm{R}=500 \Omega$ is an internal impedance (Ooi et al., 2020), $11.3 \mathrm{GHz}$ is the modulation speed. Power consumption is equal to: $E_{\text {bit }}=C V_{\text {on }}^{2} / 2+C V_{\text {off }}^{2} / 2$ and it is $5.4 \mathrm{fJ} / \mathrm{bit}$ (Shetty et al., 2015).

The ER and power consumption of the proposed modulator are better than (Lin and Helmy, 2015b, Markov et al., 2015, Zhu et al., 2014, Sadeghi et al., 2020, Das and Arya, 2021), and modulation speed has improved compared to (Markov et al., 2015, Zhu et al., 2014). The proposed modulator characteristics such as ER, $f$ (3dB), Ebit are compared with similar structures in Table 1.

Table 1

Comparison of the proposed modulator with similar modulators

\begin{tabular}{|c|c|c|c|c|c|c|}
\hline \multicolumn{2}{|l|}{ Device Type } & $\begin{array}{l}\mathrm{IL}(\mathrm{dB} / \\
\mu \mathrm{m})\end{array}$ & $\begin{array}{l}\mathrm{ER}(\mathrm{dB} / \\
\mu \mathrm{m})\end{array}$ & $\begin{array}{l}E \\
\text { (fJ) }\end{array}$ & $\begin{array}{l}\text { Modulation } \\
\text { speed(GHz) }\end{array}$ & $\begin{array}{l}\text { Device } \\
\text { Length }(\mu \mathrm{m})\end{array}$ \\
\hline \multicolumn{2}{|c|}{$\begin{array}{l}\text { ITO based Vertical structure }{ }^{(\text {Lin and }} \\
\text { Helmy, 2015b) }\end{array}$} & 0.03 & 4.8 & 14.8 & 363 & 5.53 \\
\hline \multicolumn{2}{|c|}{$\begin{array}{l}\mathrm{Au} \mathrm{VO} \mathrm{V}_{2} \text { hybrid plasmonic (Markov et al., } \\
\text { 2015) }\end{array}$} & & 8.9 & a & $>1$ & 0.56 \\
\hline \multicolumn{2}{|c|}{ TiN/Cu/ITO structure (Zhu et al., 2014) } & 0.88 & 3.95 & 400 & 11 & 1 \\
\hline \multicolumn{2}{|c|}{ Hybrid Si/ $/ \mathrm{VO}_{2}{ }^{\text {(Sadeghi et al., 2020) }}$} & 0.1 & 4.4 & a & a & 1 \\
\hline \multirow{2}{*}{$\begin{array}{l}\text { plasmonic } \\
\text { electro-absorption (Das and } \\
\text { Arya, 2021) }\end{array}$} & $\begin{array}{l}\text { ITO } \\
\text { based }\end{array}$ & 0.025 & 3.07 & 178 & 8.84 & 0.5 \\
\hline & $\begin{array}{l}\mathrm{VO}_{2} \\
\text { based }\end{array}$ & 0.651 & 5.85 & 400 & 52.6 & 0.5 \\
\hline \multicolumn{2}{|l|}{ This work } & 0.83 & 8.12 & 5.4 & 11.3 & 4.9 \\
\hline
\end{tabular}

\section{Conclusion}

The optical modulator was proposed and designed based on coupling between waveguides with vertical plasmonic structure. The graphene and ITO were used in the plasmonic region of the modulator to decrease the operating voltage and increase the light-matter interaction. The modulator had a high ER, a compact size, and low power consumption. The modulator also had a broadband performance. The modulator characteristic in comparison to other similar modulators showed significant improvement. This plasmonic 
modulator with high ER, relatively low IL, and broadband could be used compact size, energy-efficient and potentially fast on-chip communication interconnects for the photonic integrated circuit.

\section{Declarations}

\section{Funding}

No funds, grants, or other support was received.

\section{Conflicts of interest/Competing interests}

The authors have no relevant financial or non-financial interests to disclose.

\section{Availability of data and material}

'Not applicable'

\section{Code availability}

'Not applicable'

\section{Authors' contributions}

The authors' contributions are equal.

\section{Ethics approval}

\section{Consent to participate}

\section{Consent for publication}

\section{References}

1. ABDELATTY, M. Y., BADR, M. M. \& SWILLAM, M. A. 2018. Compact silicon electro-optical modulator using hybrid ITO tri-coupled waveguides. Journal of Lightwave Technology, 36, 4198-4204.

2. ALÙ, A., SILVEIRINHA, M. G. \& ENGHETA, N. 2008. Transmission-line analysis of $\varepsilon$-near-zero-filled narrow channels. Physical Review E, 78, 016604.

3. ANSELL, D., RADKO, I. P., HAN, Z., RODRIGUEZ, F. J., BOZHEVOLNYI, S. I. \& GRIGORENKO, A. N. 2015. Hybrid graphene plasmonic waveguide modulators. Nat Commun, 6, 8846.

4. BABICHEVA, V. E., KINSEY, N., NAIK, G. V., FERRERA, M., LAVRINENKO, A. V., SHALAEV, V. M. \& BOLTASSEVA, A. 2013. Towards CMOS-compatible nanophotonics: Ultra-compact modulators using alternative plasmonic materials. Optics express, 21, 27326-27337.

5. CAMPIONE, S., WOOD, M. G., SERKLAND, D. K., PARAMESWARAN, S., IHLEFELD, J., LUK, T., WENDT, J. R., GEIB, K. M. \& KEELER, G. A. 2017. Submicrometer epsilon-near-zero electroabsorption modulators enabled by high-mobility cadmium oxide. IEEE Photonics Journal, 9, 1-7. 
6. CHEE, J., ZHU, S. \& LO, G. 2012. CMOS compatible polarization splitter using hybrid plasmonic waveguide. Optics Express, 20, 25345-25355.

7. CHEN, X., WANG, Y., XIANG, Y., JIANG, G., WANG, L., BAO, Q., ZHANG, H., LIU, Y., WEN, S. \& FAN, D. 2016. A broadband optical modulator based on a graphene hybrid plasmonic waveguide. Journal of Lightwave Technology, 34, 4948-4953.

8. DAS, H. R. \& ARYA, S. C. 2021. Performance improvement of $\mathrm{VO}_{2}$ and ITO based plasmonic electroabsorption modulators at $1550 \mathrm{~nm}$ application wavelength. Optics Communications, 479, 126455.

9. DAS, S., SALANDRINO, A., WU, J. Z. \& HUI, R. 2015. Near-infrared electro-optic modulator based on plasmonic graphene. Opt Lett, 40, 1516-9.

10. DU, W., LI, K., WU, D., JIAO, K., JIAO, L., LIU, L., XIA, F., KONG, W., DONG, L. \& YUN, M. 2019. Electrically controllable directional coupler based on tunable hybrid graphene nanoplasmonic waveguide. Optics Communications, 430, 450-455.

11. ESLAMI, A., SADEGHI, M. \& ADELPOUR, Z. 2021. Plasmonic modulator utilizing graphene-HfO ${ }_{2}-I_{T O}$ stack embedded in the silicon waveguide. Optik, 227, 165608.

12. FEIGENBAUM, E., DIEST, K. \& ATWATER, H. A. 2010. Unity-order index change in transparent conducting oxides at visible frequencies. Nano letters, 10, 2111-2116.

13. GOSCINIAK, J. \& TAN, D. T. 2013. Theoretical investigation of graphene-based photonic modulators. Sci Rep, 3, 1897.

14. HAN, S., KIM, S., KIM, S., LOW, T., BRAR, V. W. \& JANG, M. S. 2020. Complete Complex Amplitude Modulation with Electronically Tunable Graphene Plasmonic Metamolecules. ACS Nano, 14, 1166-1175.

15. HUANG, B. H., LU, W. B., LI, X. B., WANG, J. \& LIU, Z. G. 2016. Waveguide-coupled hybrid plasmonic modulator based on graphene. Appl Opt, 55, 5598-602.

16. HUANG, W. P. \& MU, J. 2009. Complex coupled-mode theory for optical waveguides. Opt Express, 17, 19134-52.

17. JIANG, L., CHEN, X., KIM, K., DE VALICOURT, G., HUANG, Z. R. \& DONG, P. 2018. Electro-optic crosstalk in parallel silicon photonic Mach-Zehnder modulators. Journal of Lightwave Technology, 36, 1713-1720.

18. JIANG, W., MIAO, J. \& LI, T. 2019a. Silicon Mode-Selective Switch via Horizontal Metal-OxideSemiconductor Capacitor Incorporated With ENZ-ITO. Scientific reports, 9, 1-12.

19. JIANG, W., MIAO, J. \& LI, T. 2019b. Silicon Mode-Selective Switch via Horizontal Metal-OxideSemiconductor Capacitor Incorporated With ENZ-ITO. Sci Rep, 9, 17777.

20. JIN, L., CHEN, Q., LIU, W. \& SONG, S. 2016. Electro-absorption modulator with dual carrier accumulation layers based on epsilon-near-zero ITO. Plasmonics, 11, 1087-1092.

21. KIM, J.-S. \& KIM, J. T. 2016. Silicon electro-optic modulator based on an ITO-integrated tunable directional coupler. Journal of Physics D: Applied Physics, 49, 075101.

22. KIM, J. T. 2014. CMOS-compatible hybrid plasmonic modulator based on vanadium dioxide insulatormetal phase transition. Opt Lett, 39, 3997-4000.

23. KOCH, U., HÖSSBACHER, C., NIEGEMANN, J., HAFNER, C. \& LEUTHOLD, J. 2016. Digital plasmonic absorption modulator exploiting epsilon-near-zero in transparent conducting oxides. IEEE Photonics 
Journal, 8, 1-13.

24. KRASAVIN, A. V. \& ZAYATS, A. V. 2012. Photonic signal processing on electronic scales: electro-optical field-effect nanoplasmonic modulator. Phys Rev Lett, 109, 053901.

25. LEE, H. W., PAPADAKIS, G., BURGOS, S. P., CHANDER, K., KRIESCH, A., PALA, R., PESCHEL, U. \& ATWATER, H. A. 2014. Nanoscale conducting oxide PlasMOStor. Nano Lett, 14, 6463-8.

26. LI, Z., BAI, L., LI, X., GU, E., NIU, L. \& ZHANG, X. 2018. U-shaped micro-ring graphene electro-optic modulator. Optics Communications, 428, 200-205.

27. LIN, C. \& HELMY, A. S. 2015a. Dynamically reconfigurable nanoscale modulators utilizing coupled hybrid plasmonics. Scientific reports, 5, 1-10.

28. LIN, C. \& HELMY, A. S. 2015b. Dynamically reconfigurable nanoscale modulators utilizing coupled hybrid plasmonics. Sci Rep, 5, 12313.

29. LIN, C. \& HELMY, A. S. 2015c. Dynamically reconfigurable nanoscale modulators utilizing coupled hybrid plasmonics. Scientific reports, 5, 12313.

30. LIU, M., YIN, X., ULIN-AVILA, E., GENG, B., ZENTGRAF, T., JU, L., WANG, F. \& ZHANG, X. 2011a. A graphenebased broadband optical modulator. Nature, 474, 64-7.

31. LIU, M., YIN, X., ULIN-AVILA, E., GENG, B., ZENTGRAF, T., JU, L., WANG, F. \& ZHANG, X. 2011b. A graphenebased broadband optical modulator. Nature, 474, 64-67.

32. LOU, F., DAI, D. \& WOSINSKI, L. 2012. Ultracompact polarization beam splitter based on a dielectrichybrid plasmonic-dielectric coupler. Optics letters, 37, 3372-3374.

33. MAHMOUD, M., BOTTENFIELD, C., CAI, L. \& PIAZZA, G. Fully integrated lithium niobate electro-optic modulator based on asymmetric Mach-Zehnder interferometer etched in LNOI platform. 2017 IEEE Photonics Conference (IPC), 2017. IEEE, 223-224.

34. MARKOV, P., APPAVOO, K., HAGLUND, R. F., JR. \& WEISS, S. M. 2015. Hybrid Si-VO(2)-Au optical modulator based on near-field plasmonic coupling. Opt Express, 23, 6878-87.

35. OOI, K. J., ANG, Y., ZHAI, Q., SUN, X., XING, P., ONG, C., ANG, L. \& TAN, D. T. 2020. Dirac terahertz plasmonics in two and three dimensions. Optics Communications, 462, 125319.

36. PRESTON, K., MANIPATRUNI, S., GONDARENKO, A., POITRAS, C. B. \& LIPSON, M. 2009. Deposited silicon high-speed integrated electro-optic modulator. Opt Express, 17, 5118-24.

37. QIU, F. \& HAN, Y. 2021. Electro-optic polymer ring resonator modulators. Chinese Optics Letters, 19, 041301.

38. SADEGHI, M., JANJAN, B., HEIDARI, M. \& ABBOTT, D. 2020. Mid-infrared hybrid Si/VO 2 modulator electrically driven by graphene electrodes. Optics express, 28, 9198-9207.

39. SENSALE-RODRIGUEZ, B., YAN, R., RAFIQUE, S., ZHU, M., LI, W., LIANG, X., GUNDLACH, D., PROTASENKO, V., KELLY, M. M., JENA, D., LIU, L. \& XING, H. G. 2012. Extraordinary control of terahertz beam reflectance in graphene electro-absorption modulators. Nano Lett, 12, 4518-22.

40. SHAH, M. K., LU, R. \& LIU, Y. 2018. Enhanced performance of ITO-assisted electro-absorption optical modulator using sidewall angled silicon waveguide. IEEE Transactions on Nanotechnology, 17, 412-418. 
41. SHETTY, A., ROUL, B., MUKUNDAN, S., MOHAN, L., CHANDAN, G., VINOY, K. \& KRUPANIDHI, S. 2015. Temperature dependent electrical characterisation of $\mathrm{Pt} / \mathrm{HfO} 2 / \mathrm{n}-\mathrm{GaN}$ metal-insulator-semiconductor (MIS) Schottky diodes. AIP Advances, 5, 097103.

42. SHIN, J.-S. \& KIM, J. T. 2015. Broadband silicon optical modulator using a graphene-integrated hybrid plasmonic waveguide. Nanotechnology, 26, 365201.

43. SUN, F., XIA, L., NIE, C., QIU, C., TANG, L., SHEN, J., SUN, T., YU, L., WU, P. \& YIN, S. 2019. An all-optical modulator based on a graphene-plasmonic slot waveguide at $1550 \mathrm{~nm}$. Applied Physics Express, 12, 042009.

44. WONG, H. M. \& HELMY, A. S. 2017. Performance enhancement of nanoscale VO 2 modulators using hybrid plasmonics. Journal of Lightwave Technology, 36, 797-808.

45. WOOD, M. G., CAMPIONE, S., PARAMESWARAN, S., LUK, T. S., WENDT, J. R., SERKLAND, D. K. \& KEELER, G. A. 2018. Gigahertz speed operation of epsilon-near-zero silicon photonic modulators. Optica, 5, 233236.

46. WU, Z. \& XU, Y. 2018. Design of a graphene-based dual-slot hybrid plasmonic electro-absorption modulator with high-modulation efficiency and broad optical bandwidth for on-chip communication. Appl Opt, 57, 3260-3267.

47. XU, Q., SCHMIDT, B., PRADHAN, S. \& LIPSON, M. 2005. Micrometre-scale silicon electro-optic modulator. Nature, 435, 325-7.

48. YE, C., KHAN, S., LI, Z. R., SIMSEK, E. \& SORGER, V. J. 2014. $\lambda$-size ITO and graphene-based electro-optic modulators on SOI. IEEE Journal of Selected Topics in Quantum Electronics, 20, 40-49.

49. YE, C., LIU, K., SOREF, R. A. \& SORGER, V. J. 2015. A compact plasmonic MOS-based $2 \times 2$ electro-optic switch. Nanophotonics, 4, 261-268.

50. ZHU, J., CHENG, J., ZHANG, L. \& LIU, Q. H. 2017. Modeling of 2D graphene material for plasmonic hybrid waveguide with enhanced near-infrared modulation. Materials Letters, 186, 53-56.

51. ZHU, S., LO, G. Q. \& KWONG, D. L. 2014. Design of an ultra-compact electro-absorption modulator comprised of a deposited TiN/HfO(2)/ITO/Cu stack for CMOS backend integration. Opt Express, 22, $17930-47$.

\section{Figures}




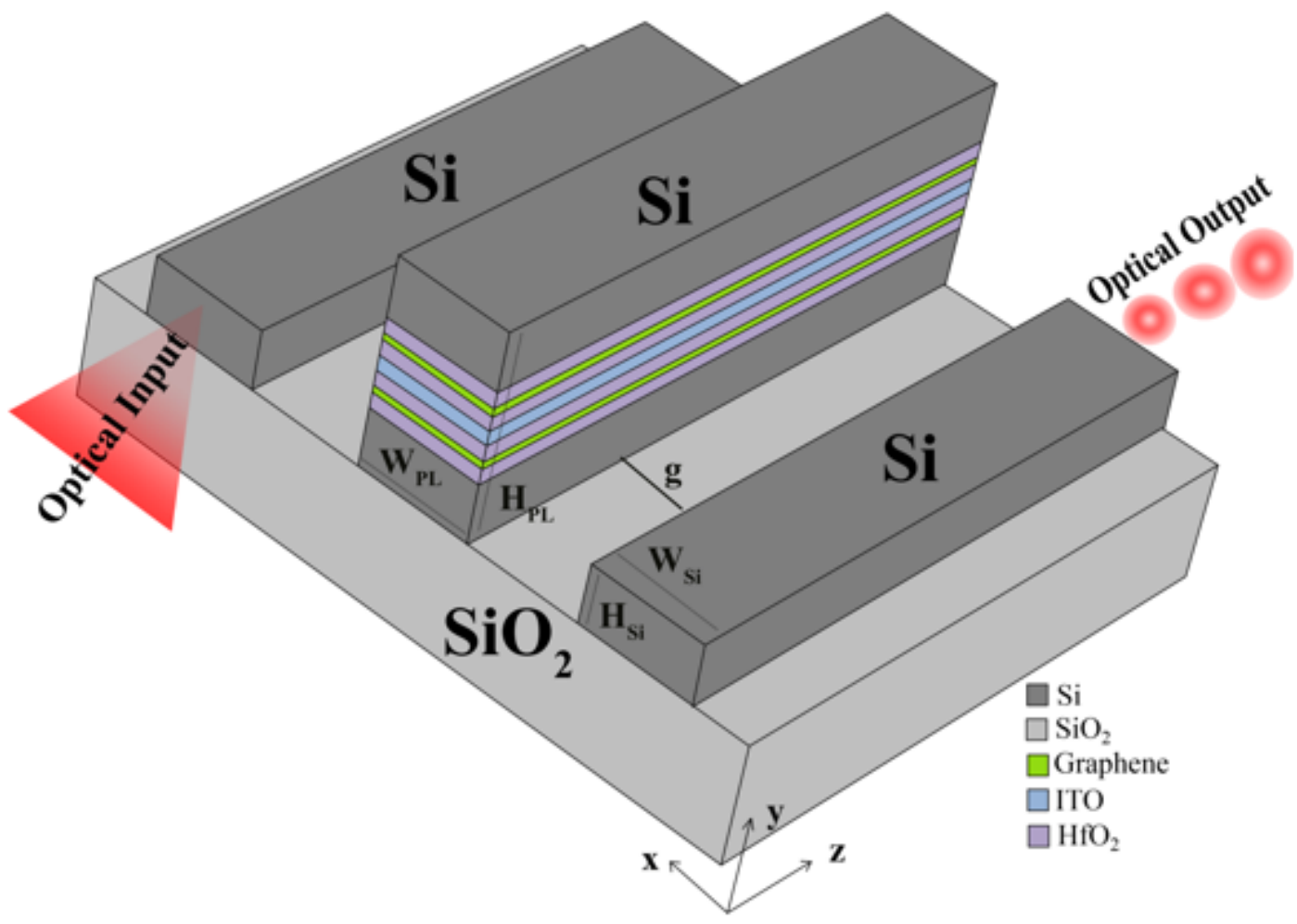

Figure 1

$3 \mathrm{D}$ view of the proposed structure 


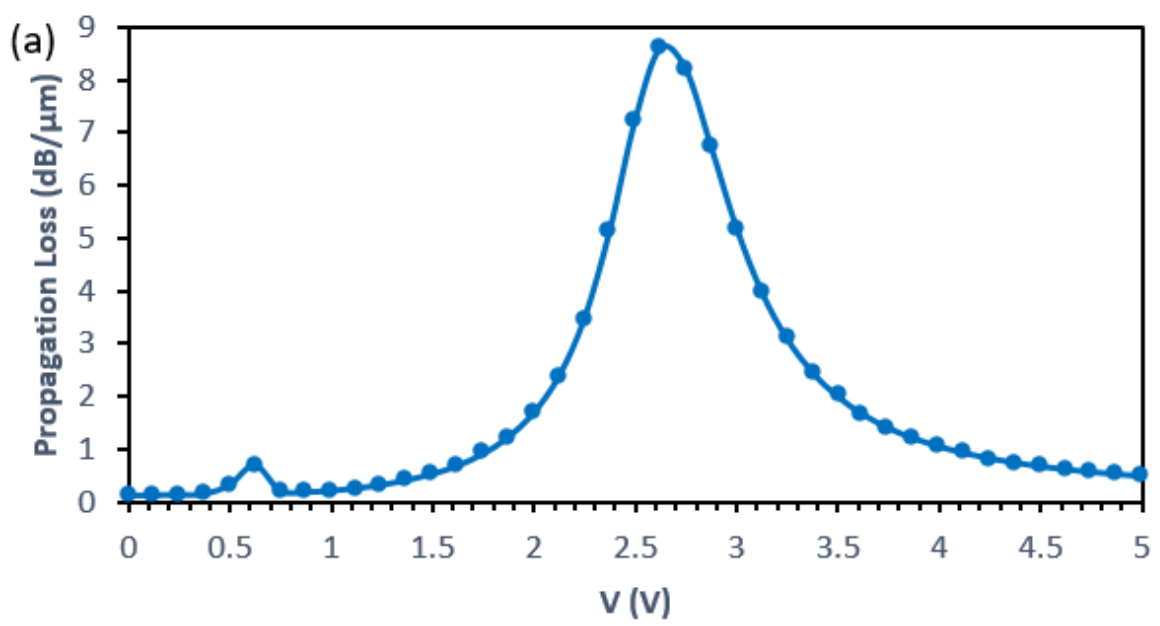

(b)
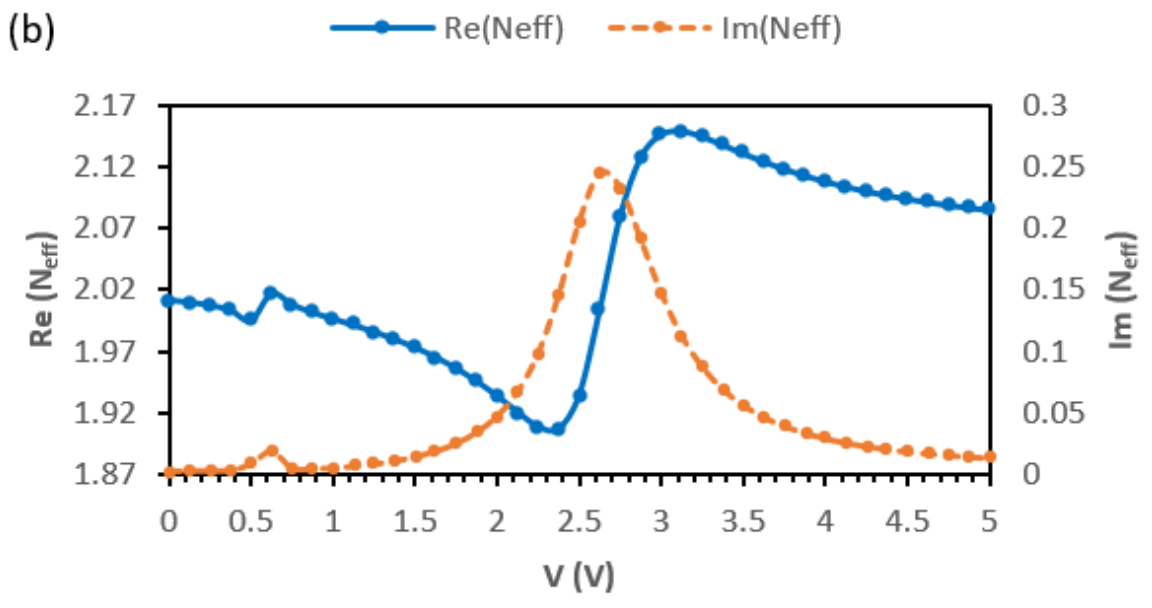

(c)
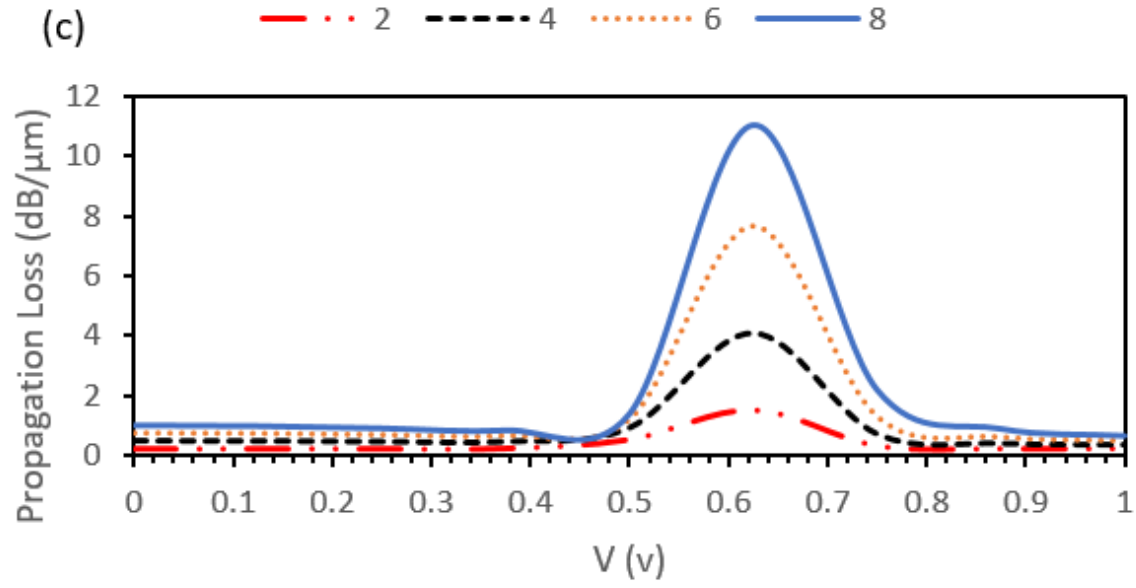

Figure 2

a) propagation loss for different voltage values (monolayer graphene) b) The real and imaginary part of the refractive index (graphene monolayer) c) propagation loss for different voltage values (multilayer graphene: $2,4,6,8$ layer) $\left(\mathrm{W}_{\mathrm{PL}}=130 \mathrm{~nm}, \mathrm{H}_{\mathrm{ITO}}=10 \mathrm{~nm}, \mathrm{H}_{\mathrm{HfO} 2}=10 \mathrm{~nm}\right)$ 


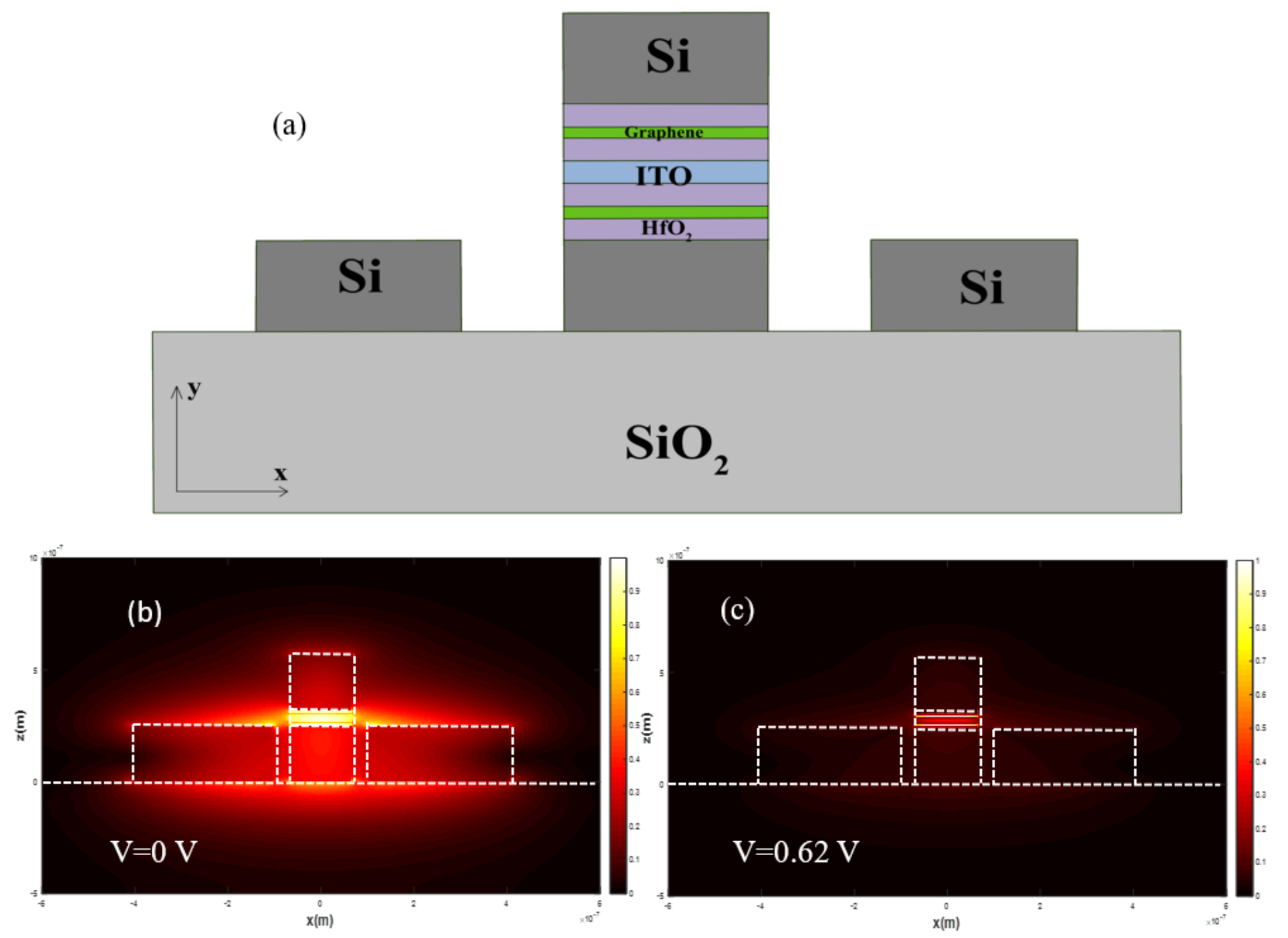

Figure 3

a) Proposed modulators cross-section view, the intensity of the guided mode of the electric field in b) On state $(V=0) c)$ Off state $(V=0.62 \mathrm{~V})\left(\mathrm{W}_{\mathrm{Si}}=300 \mathrm{~nm}, \mathrm{H}_{\mathrm{Si}}=250 \mathrm{~nm}, \mathrm{H}_{\mathrm{PL}}=566 \mathrm{~nm}, \mathrm{~W}_{\mathrm{PL}}=130 \mathrm{~nm}, \mathrm{H}_{\text {ITO }}=10 \mathrm{~nm}\right.$, $\mathrm{H}_{\mathrm{HfO} 2}=10 \mathrm{~nm}, \mathrm{~g}=30 \mathrm{~nm}$ ) 
(a) $\longrightarrow$ Neff P lasmonic Waveguide $\quad$--๑-- Neff Si Waveguide

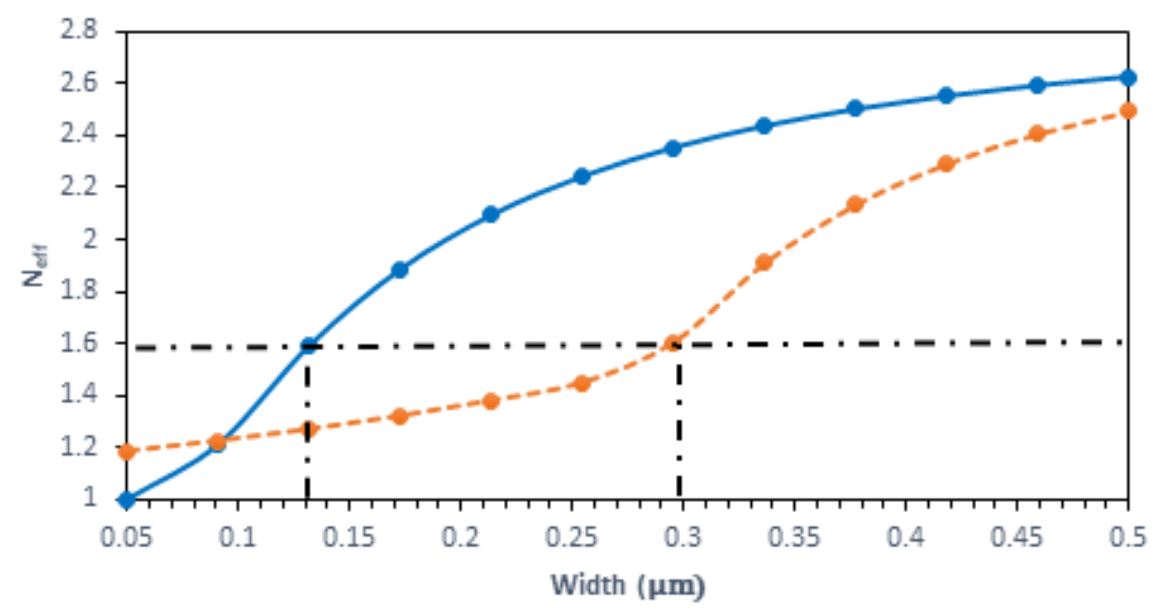

(b) $\longrightarrow \mathrm{N} 1 \longrightarrow \mathrm{N} 2 \longrightarrow \mathrm{N} 3 \longrightarrow(\mathrm{N} 1+\mathrm{N} 3) / 2$

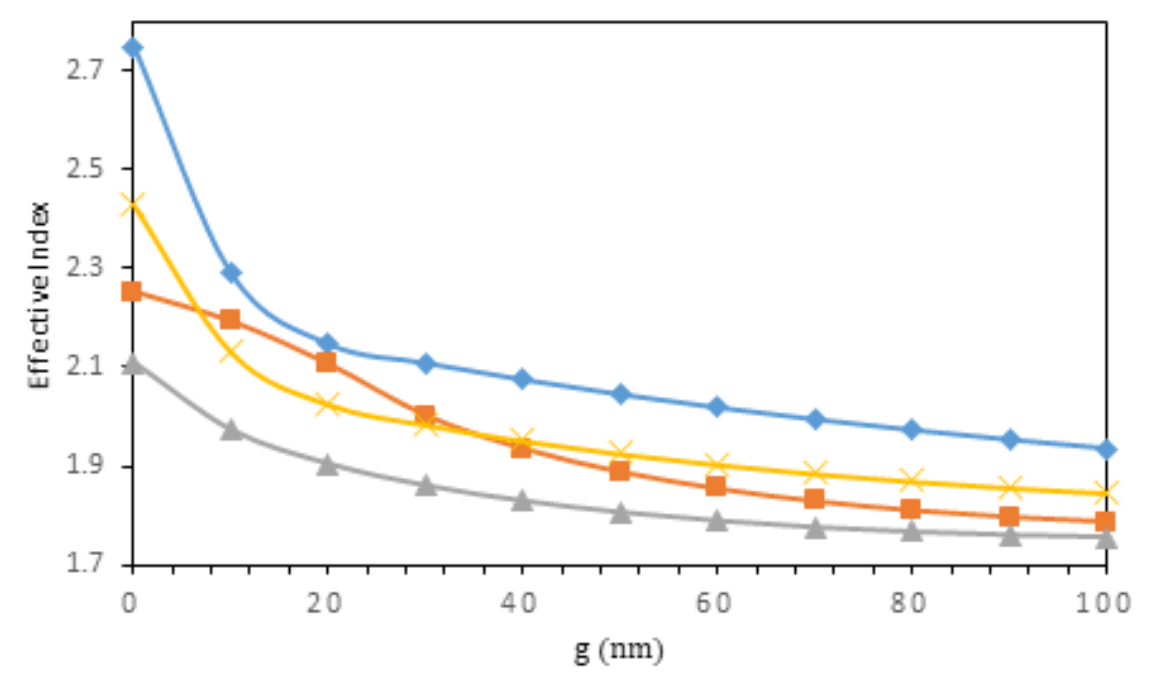

\section{Figure 4}

a) The effective index of the silicon waveguide and plasmonic waveguide $(\mathrm{V}=0 \mathrm{~V})$ for the different values of wave guides width $b$ ) the effective index of eigenmode for different gap between the Si and plasmonic waveguides $\left(\mathrm{H}_{\mathrm{Si}}=250 \mathrm{~nm}, \mathrm{H}_{\mathrm{PL}}=566 \mathrm{~nm}, \mathrm{H}_{\mathrm{ITO}}=10 \mathrm{~nm}, \mathrm{H}_{\mathrm{HfO} 2}=10 \mathrm{~nm}\right)$. 


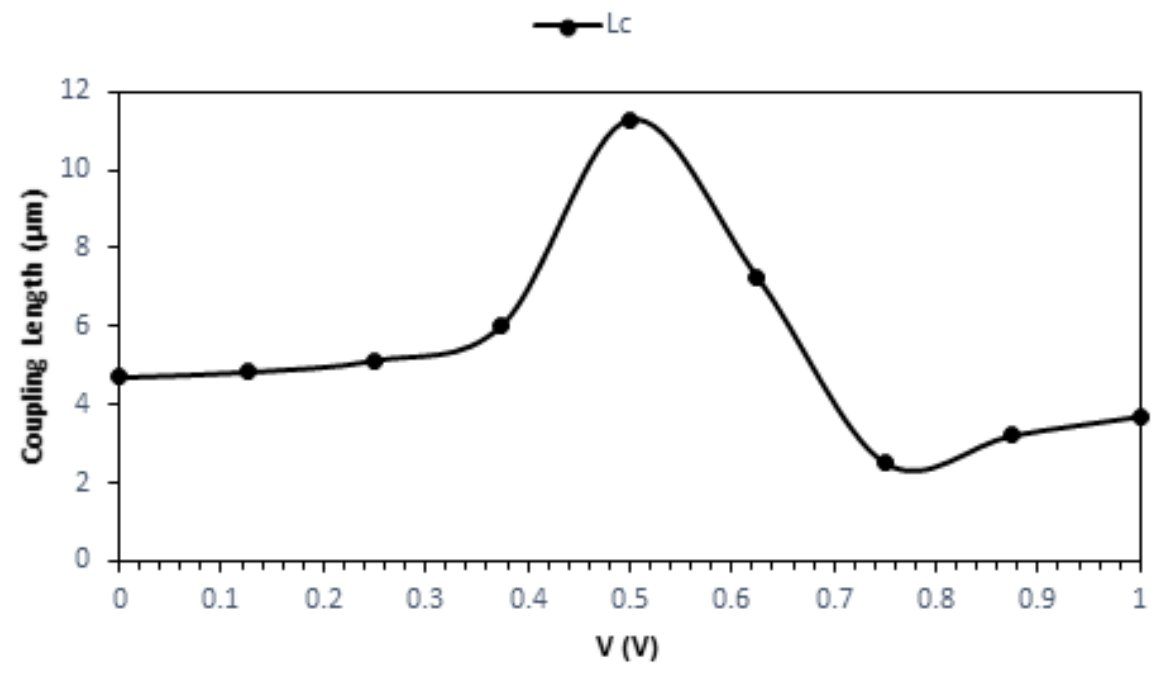

Figure 5

The coupling length with voltage change
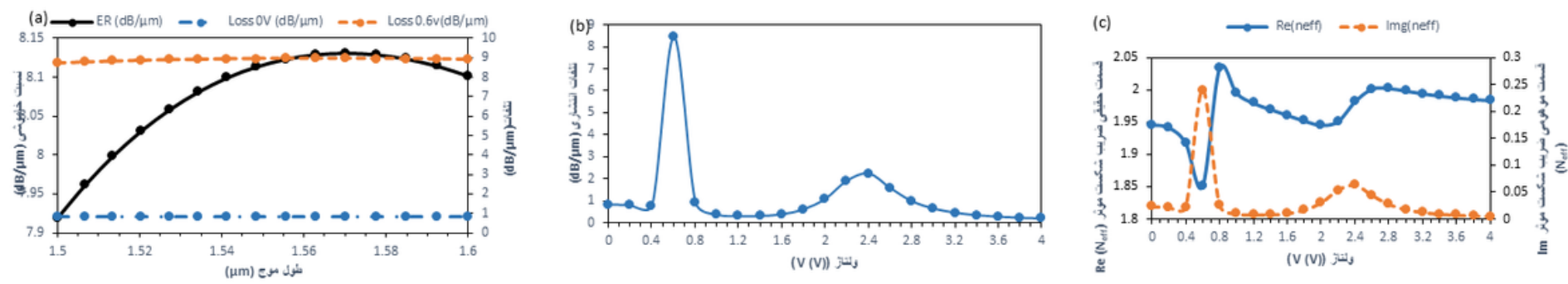

Figure 6

a) ER as a function of wavelength b) propagation loss for different voltage values $c$ ) The real and imaginary part of the refractive index 

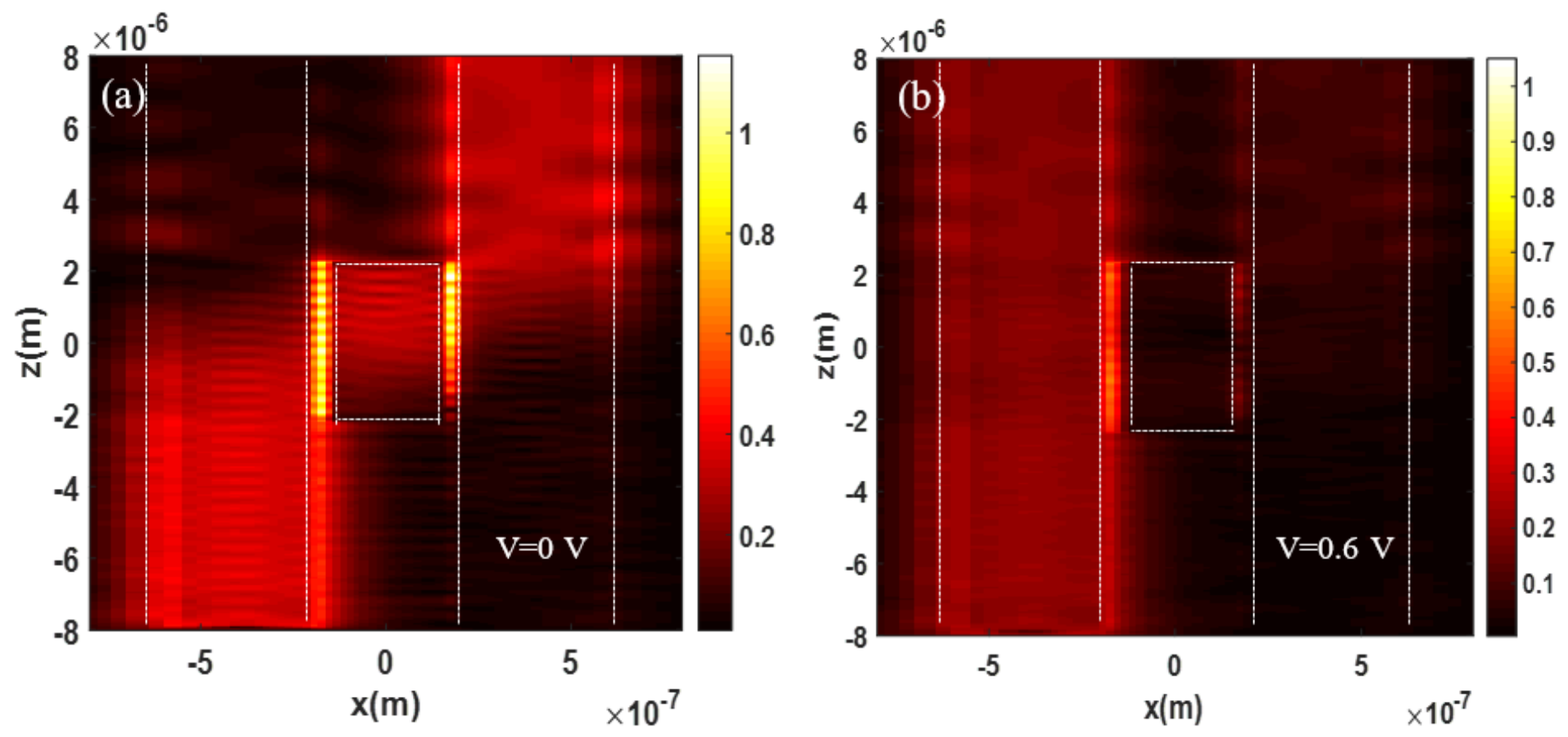

Figure 7

a) The Electrical field intensity of the guided mode in the On-State b) and Off-State. 